\title{
Impact of SST diurnal cycle on ENSO asymmetry
}

\author{
Fangxing Tian ${ }^{1,2}$ - Jin-Song von Storch ${ }^{1} \cdot$ Eileen Hertwig ${ }^{1}$
}

Received: 2 October 2017 / Accepted: 14 May 2018 / Published online: 1 June 2018

(c) The Author(s) 2018

\begin{abstract}
The dominant mode of inter-annual variability in the tropical Pacific is El Niño-Southern Oscillation (ENSO). ENSO is not symmetric in the sense that El Niño is generally stronger than La Niña. However, many CMIP5 models, including the Max Planck Institute Earth System Model (MPI-ESM), produce an almost symmetric ENSO. This paper shows that, when resolving the intra-daily air-sea interactions by coupling the atmospheric and oceanic model components once per hour, the simulated ENSO asymmetry is improved. The improvement is closely related to the simulated diurnal cycle of sea surface tempreature (SST). In the central tropical Pacific, the simulated diurnal range of SST is about $0.2{ }^{\circ} \mathrm{C}$, up to $10 \%$ of SST anomalies of the simulated ENSO events. During El Niño events, the diurnal cycle of SST anomalies enhances the atmospheric moist instability, whereby triggering more convection in the central tropical Pacific. During La Niña and normal years, however, the mean convection is not changed by the included diurnal cycle of SST anomalies. As a result, the anomalies of the trades, which are directly related to the convection, are stronger during El Niño years than that during La Niña years, making El Niño to be stronger than La Niña via Bjerknes feedback. These results obtained with a low resolution MPI-ESM are further confirmed by simulation with the same model at higher spatial resolutions, suggesting that the role of the intradaily air-sea interactions for the ENSO asymmetry is independent of model resolutions.
\end{abstract}

\section{Introduction}

The amplitude of SST anomalies is generally stronger during El Niño than during La Niña events. This difference is referred to as ENSO asymmetry (Hoerling et al. 1997; Burgers and Stephenson 1999). The asymmetry also has a vertical structure in the ocean. In the western Pacific, the negative anomalies of the upper ocean heat content during a strong El Niño are much stronger than the corresponding positive anomalies during a strong La Niña (Tang and Hsieh 2003). The ENSO asymmetry is considered to be an important characteristics of ENSO. Underestimation of the ENSO asymmetry, however, is a common problem of Coupled General Circulation Modules (CGCMs) in phase 3 of Coupled Model Intercomparation Project (CMIP3) and remained a problem in CMIP5 (Zhang and Sun 2014; Zhang et al. 2009). This paper addresses this problem by examine the impact of intra-diurnal air-sea interaction processes on

Fangxing Tian

fangxing.tian@reading.ac.uk

Max Planck Institute for Meteorology, Hamburg, Germany

2 National Centre for Atmospheric Science, Department of Meteorology, University of Reading, Reading, UK
ENSO asymmetry induced by coupling the atmosphere and the ocean once per hour.

The causes of the ENSO asymmetry have been studied by many previous works. For example, some studies suggest that stronger El Niño events are related to stronger warming tendency due to non-linear dynamics related to thermal advection, which ultimately generates the ENSO asymmetry (Timmermann et al. 2003; An and Jin 2004; An et al. 2005). Others suggest that the ENSO asymmetry results from the fact that effects of the tropical instability waves are different during El Niño and La Niña years. It is shown that the tropical instability waves tend to reduce the cold-tongue intensity. This effects are stronger during La Niña than during El Niño (Yu and Liu 2003; Vialard et al. 2001; An et al. 2008).

Though previous studies showed that the ocean processes are important for the ENSO asymmetry, it is difficult to separate the effects from atmosphere and ocean in a coupled air-sea system. Especially in the tropics, air-sea interactions play an important role for ENSO and ENSO asymmetry (Guilyardi et al. 2004; Watanabe et al. 2011; Kang and Kug 2002; Zhang et al. 2009; Hoerling et al. 1997; Zhang and Sun 2014; Im et al. 2015; Kang and Kug (2002) and Im et al. (2015) showed that the ENSO asymmetry is related to the eastward shift of wind stress anomalies in El Niño 
phase compared to La Niña phase. The shift of wind stress is a consequence of the deep convection (Zhang et al. 2009): During El Niño, the convection anomalies are located over the central and eastern tropical Pacific, whereas, during La Niña, the convection anomalies are confined to the western central Pacific. This shift of convection anomalies from central and eastern Pacific to the western Pacific was attributed to the dependence of convection on the background SST (Hoerling et al. 1997). This role of SST-dependent convection in ENSO asymmetry was further confirmed by Zhang and Sun (2014) using wind-forced GCM experiments.

Even though these works have considered the effects of air-sea interactions on ENSO asymmetry, most of them are based on monthly mean variables of observations or model output, without addressing the role of diurnal cycle of SST anomalies and the related intra-daily air-sea interactions.

Recently, the diurnal cycle of SST anomalies has been extensively studied using both observations (Gille 2012; Clayson and Bogdanoff 2013; Weller et al. 2014; Yang et al. 2015) and models (Danabasoglu et al. 2006; Bernie et al. 2008; Terray et al. 2012; Masson et al. 2012; Li et al. 2013; Thushara and Vinayachandran 2014; Tian et al. 2016). It is found that, in the tropics, the annual mean of diurnal range of SST can be as large as $0.5^{\circ} \mathrm{C}$ (Kennedy et al. 2007), with maximum values up to $3{ }^{\circ} \mathrm{C}$ (Clayson and Bogdanoff 2013). Meehl et al. (2001) and Tian et al. (2016) suggest that processes on shorter time and smaller space scales may influence processes with longer and larger scales in continuous scale interactions. The intra-daily air-sea interactions are important high-frequency processes in the coupled air-sea system, which might affect processes with time scales longer than one day, such as ENSO. For example, when the diurnal cycle of SST anomalies is included, the model's El Niño has a more realistic evolution in its developing and decaying phases, a stronger amplitude and a shift towards lower frequencies (Terray et al. 2012).

The simulated ENSO asymmetry is also affected when increasing the air-sea coupling frequency from daily to hourly (Masson et al. 2012). Masson et al. (2012) suggested that the simulated ENSO asymmetry is due to the thin surface layer of $1 \mathrm{~m}$ depth in their model. However, the processes by which the intra-daily air-sea interactions affect the ENSO asymmetry were not studied. These processes are the focus here. We aim to reveal the responsible mechanisms by which the intra-daily air-sea interactions affect the simulated ENSO asymmetry using the Max Planck Institute Earth System Model (MPI-ESM).

This paper is organized as follows. In Sect. 2, the methods and observations used in the analysis are introduced. The model performance in reproducing the intra-daily air-sea interactions is evaluated. Section 3 describes the ENSO asymmetry in observations, and in a daily- and a hourlycoupled experiment. A mechanism of how the intra-daily air-sea feedback influences the ENSO asymmetry is proposed. Conclusions are given in Sect. 4.

\section{Experiments, data and methods}

The experiments are performed with the latest version of the Max Planck Institute for Meteorology Earth System Model (MPI-ESM-1.2), which consists of the general circulation models for the atmosphere (ECHAM6, Stevens et al. (2013)) and for the ocean (MPIOM, Jungclaus et al. (2006), Jungclaus et al. (2010)). ECHAM6 is run at T63 horizontal resolution (approximately $1.875^{\circ}$ on a Gaussian grid) with 47 vertical levels. MPIOM uses a bipolar grid with horizontal resolution of about $1.5^{\circ}$ and 40 vertical levels, the first layer is $12 \mathrm{~m}, 8$ layers are within the upper $90 \mathrm{~m}$ and 20 are within the upper $600 \mathrm{~m}$.This model is referred to as the low-resolution model, MPI-ESM-LR. To assess the dependence of the results on model resolution, a higher-resolution version, MPI-ESM-HR is also used. The atmospheric resolution is then enhanced to $\mathrm{T} 127$ (approximately $0.95^{\circ}$ on a Gaussian grid), and the oceanic one is enhanced to $0.4^{\circ}$.

Using MPI-ESM-1.2, we perform two experiments that are identical except for the coupling frequency. The first one has a coupling frequency of once per day and is called Daily Coupling (DC) experiment. The second experiment has a coupling frequency of once per hour and is called Hourly Coupling (HC) experiment. Each experiment is run for 250 years under pre-industrial (1850) boundary conditions. In the MPI-ESM, the atmospheric component ECHAM6 and the oceanic component MPIOM are coupled via the OASIS3 coupler. The air-sea fluxes of momentum, heat and fresh water are calculated within ECHAM6, whereby making use of the SST and other sea-ice related quantities (i.e. sea-ice distribution) provided by MPIOM. In experiment DC, in which the coupling time step of 1 day is longer than the time steps of ECHAM6 (10 min) and MPIOM (1 h), ECHAM6 uses SST and sea-ices related quantities averaged over one day to calculate the air-sea fluxes at consecutive ECHAM6 time steps within that day. The averages of these fluxes are passed to MPIOM. In experiment HC, in which the coupling time step is longer than the time step of ECHAM6 but equals the time step of MPIOM, ECHAM6 uses hourly instantaneous SST and sea-ice related quantities to calculate the air-sea fluxes at consecutive ECHAM6 time steps within one hour. The averages of these fluxes are passed to MPIOM. Interaction between the atmosphere and ocean occurs only on time scales longer than the coupling time step. More details on the air-sea fluxes in experiments DC and $\mathrm{HC}$ can be found in (Tian et al. 2016).

Since the Hadley Centre Sea Ice and SST (HadISST) dataset (Rayner et al. 2003) covers only 100 years, the analyses on the simulated climate state of ENSO, including 
the ENSO-related OLR (outgoing longwave radiation) and wind stress, are concentrated on the last 100 years of the two experiments. Composites are derived based on the monthly Niño-3 Index (i.e. SST averaged over the region $5^{\circ} \mathrm{S}-5^{\circ} \mathrm{N}$, $\left.150^{\circ}-90^{\circ} \mathrm{W}\right)$. The domain of the composites covers the tropical Pacific $\left(30^{\circ} \mathrm{S}-30^{\circ} \mathrm{N}, 100^{\circ} \mathrm{E}-60^{\circ} \mathrm{W}\right)$. To study the temporal variations of the skewness-one characteristic of asymmetry, the entire 250 years of experiments are used. To assess the convective activity during different phases of ENSO, monthly OLR from the ERA-Interim dataset (Dee et al. 2011) for the period 1979-2015 are used.

The composite related to the El Niño phase is obtained when the Niño- $3\left(5^{\circ} \mathrm{S}-5^{\circ} \mathrm{N}, 150^{\circ} \mathrm{W}-90^{\circ} \mathrm{W}\right)$ index is larger than $-0.5^{\circ} \mathrm{C}$ (dashed lines above zero in Fig. 1); the composite related to the La Niña phase is obtained when the Niño-3 index is smaller than $-0.5{ }^{\circ} \mathrm{C}$ (dashed lines below zero). The sum of the composites of El Niño and La Niña phases is used to measure the ENSO asymmetry. To understand the air-sea feedback processes that affect the ENSO asymmetry, this work also composes the anomalies of zonal wind stress and longwave cloud forcing (LWCF) in the same way as for the SST anomalies. The LWCF is defined as the full sky OLR minus the clear sky OLR, hence represents the effect of convection. In this study, we take the downward OLR as positive, therefore, the positive values of LWCF indicate stronger convection. Anomalies of zonal wind stress and LWCF are obtained by subtracting the monthly climatological values from the respective timeseries in experiment $\mathrm{HC}$ and DC.

To study the different effects of diurnal cycle of SST anomalies on the convection in normal years, El Niño and La Niña years, additional 9 pairs hourly coupled ( $\mathrm{HCi})$ and daily coupled (DCi) runs are compiled over a time period of one year. To make the HCi and DCi more comparable, each pair of experiments is performed using different coupling frequency but the same initial state. The initial states are selected based on the Niño-3 index in experiment HC (Fig. 1c), and correspond to the states when the Niño-3 Index is close to zero, and to its maximum and minimum values, respectively. The selected Neutral years are marked by black dots, El Niño years by red dots and La Niña years by blue dots. Hourly output of these pairs of experiments is stored for further analysis.

Since the convection, indicated by LWCF, is normally generated when the atmosphere is moist and unstable, it's worth to study the response of atmospheric moist instability to the diurnal cycle of SST anomalies. To assess the diurnal cycle of instability of the moist air in $\mathrm{HCi}$ and $\mathrm{DCi}$, we use the K-index developed by George (2014). K-index is widely used to asses the instability of moist air (Serbis et al. 2013; Matsangouras et al. 2016; Tian and Fan 2013), and is defined as:

K-index $=(\mathrm{T} 850-\mathrm{T} 500)+\mathrm{D} 850-(\mathrm{T} 700-\mathrm{D} 700)$,

where T850, T700 and T500 are the temperature at 850 , 700 and $500 \mathrm{hPa}$. D850 and D700 are the dew point at 850 and $700 \mathrm{hPa}$. In the atmosphere, both lapse rate and moisture are important for the moist instability. K-index takes into account three components important for moist instability: temperature lapse rate (T850-T500), lower tropospheric humidity (D850) and $700 \mathrm{hPa}$ dew point depression (T700-D700). The latter quantifies the humidity at 700 $\mathrm{hPa}$. A smaller difference of (T700-D700) is related to more moisture at $700 \mathrm{hPa}$, indicating higher instability.
Fig. 1 100-year monthly time series of Niño-3 index in a observation, b experiment DC and $\mathbf{c}$ HC. Black dashed lines denote $0.5^{\circ} \mathrm{C}$ and $-0.5^{\circ} \mathrm{C}$ used to calculate the composites $\mathrm{C}_{\text {EINino }}$ and $\mathrm{C}_{\text {LaNina }}$. Dots indicate the selected El Niño (red), La Niña (blue) and Neutral years (black) for $\mathrm{HCi}$ and $\mathrm{DCi}$

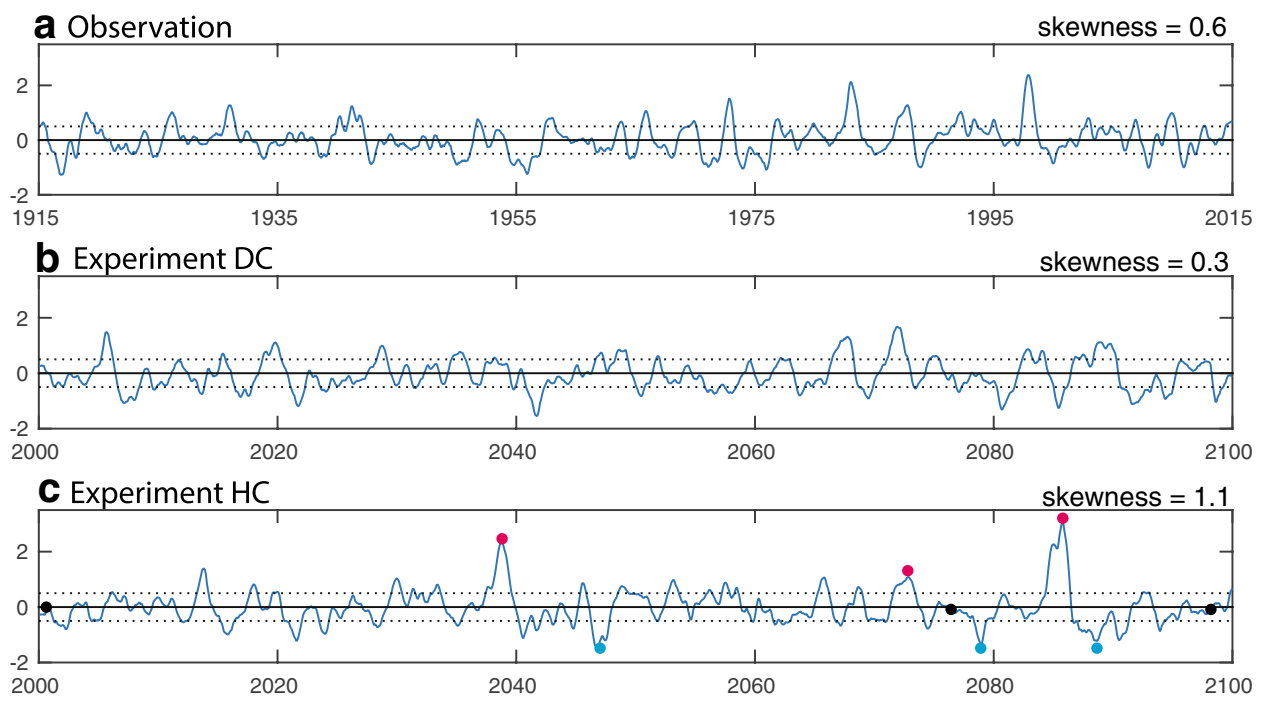




\section{Results}

\subsection{Diurnal cycles in the hourly coupled MPI-ESM}

In reality, the atmosphere is directly influenced by the skin temperature of the ocean, which is reported to have significant diurnal variation (Gille 2012; Yang et al. 2015). However, in most of the oceanic models, the SST, which is the model skin temperature, is the temperature of the first model layer. For example, the first model layer of the oceanic component of MPI-ESM is $12 \mathrm{~m}$ deep, which can store much more heat than a thinner surface layer, thus the diurnal cycle of SST anomalies in the model is generally weaker than that in observation (Danabasoglu et al. 2006; Bernie et al. 2008).

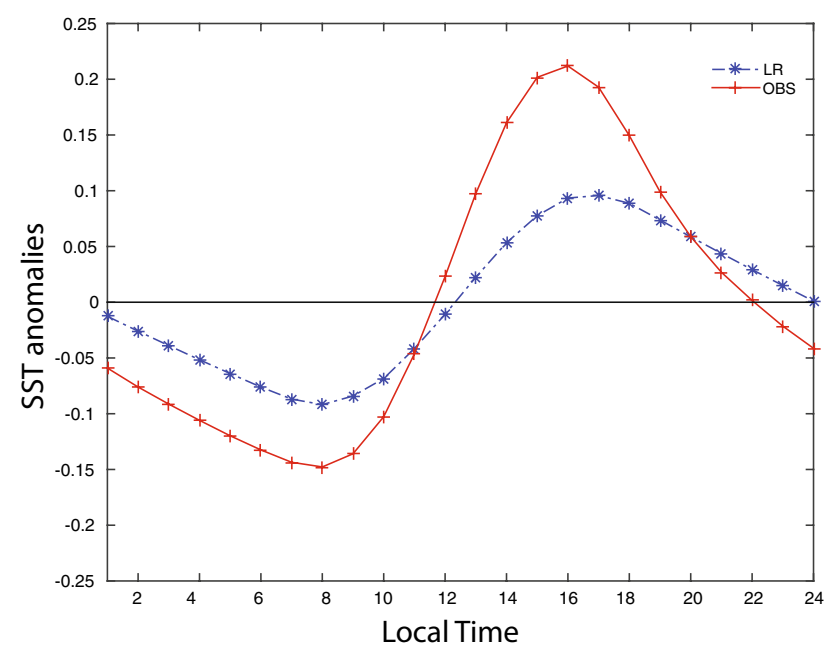

Fig. 2 Diurnal cycle of the SST (in $0.5{ }^{\circ} \mathrm{C}$ ) as anomalies relative to the long-term mean in observation (red) and in models (blue) obtained from a grid point near $\left(0^{\circ} \mathrm{C}, 140^{\circ} \mathrm{W}\right)$
To have an idea about the ability of MPI-ESM in reproducing the intra-daily air-sea interactions, we compare the simulated diurnal cycle of net heat flux and SST with those of observations. The comparison is done at a grid point near $\left(0^{\circ}, 140^{\circ} \mathrm{W}\right)$, where a mooring from the Tropical Atmosphere Ocean (TAO) project is located. This mooring is chosen because it provides continus hourly data over the longest period of more than 4 years (1991.5-1995.9).

The mooring observation (Fig. 2) shows the diurnal cycle of SST anomalies (red) increases in the daytime (around 8 AM-4 PM), reaching the maximum of $0.2^{\circ} \mathrm{C}$, and decreases in the nighttime (around $4 \mathrm{PM}-8 \mathrm{AM}$ ), reaching the minimum of $-0.15^{\circ} \mathrm{C}$ at $8 \mathrm{AM}$. For MPI-ESM (blue in Fig. 2), the basic character of the diurnal cycle of SST anomalies is reproduced in the hourly coupled experiments. The simulated diurnal range of SST (Daily maximum-Daily minimum) is about $0.2{ }^{\circ} \mathrm{C}$, about $10 \%$ of the composited SST anomalies during ENSO events in Fig. 6. However, the diurnal range is underestimated by $0.15{ }^{\circ} \mathrm{C}$ in comparison with the observation, likely due to the too thick surface layer of $12 \mathrm{~m}$.

The spatial distribution of the simulated diurnal range of SST is shown in Fig. 3. The diurnal range of SST is larger than $0.15^{\circ}$ in the tropical ocean and has the maximum in the eastern tropical Pacific. The large diurnal range of SST in the eastern tropical Pacific is related to shallower mixed layer depth there, both in the observation and in the model.

The relation between the net heat flux and the oceanic potential temperature is shown in Fig. 4 for the same grid point as in Fig. 2. The upper panel shows 10-day time series of the net heat flux. The corresponding oceanic potential temperature (bottom panel) shows that the upper ocean temperature starts to increase when the net heat flux becomes positive in the morning and reaches its peak around 4 PM. The warming of the upper ocean reaches 10-30 m depth and
Fig. 3 Long-term mean of the difference between day maximum SST and day minimum SST $\left({ }^{\circ} \mathrm{C}\right)$ (daymax - daymin) in experiment $\mathrm{HC}$

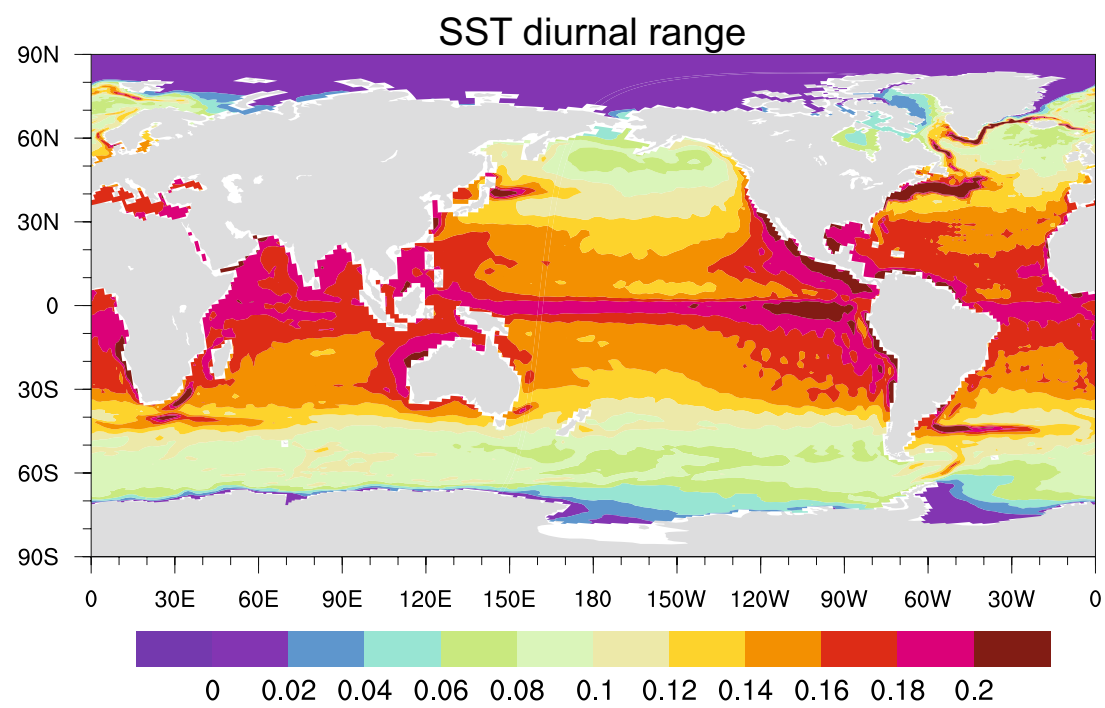


Fig. 4 a Hourly net heat flux (in $\mathrm{W} / \mathrm{m}^{2}$, black solid) from a grid point near $\left(0^{\circ}, 140^{\circ} \mathrm{W}\right)$ in experiment HC. b Hourly upper ocean potential temperature (in $\left.{ }^{\circ} \mathrm{C}\right)$ at grid point near $\left(0^{\circ}\right.$, $140^{\circ} \mathrm{W}$ ) in experiment $\mathrm{HC}$. The numbers on the $x$ axis indicate 4 $\mathrm{PM}$ of each day

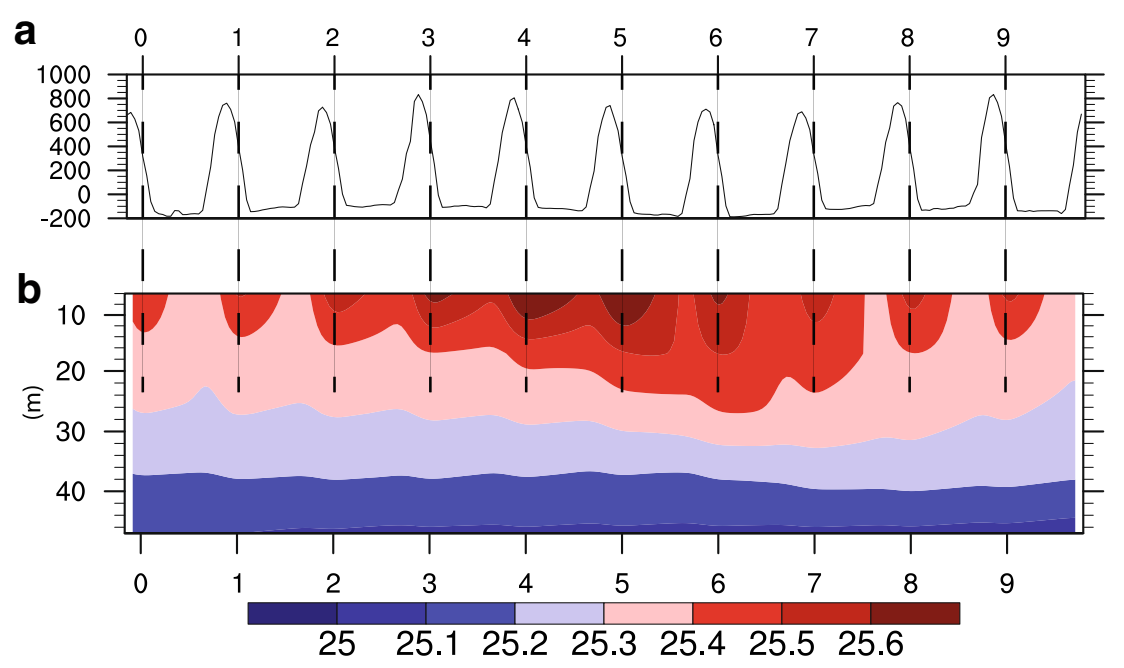

lasts until around $6 \mathrm{AM}$ after the peak in heat flux because of the large heat capacity of the water. Therefore, MPI-ESM is capable to partly simulate the diurnal cycle of the SST and also the diurnal variation of ocean potential temperature of more than two model layers $(22 \mathrm{~m})$.

As hourly coupled MPI-ESM is able to produce the diurnal cycle of SST anomalies, we assume that the simulated diurnal cycle of SST anomalies is able to affect intra-daily air-sea interactions and with that air-sea interactions on longer time scales and finally the ENSO asymmetry. These effects can be measured by the difference between experiment HC and DC, because the air-sea interactions on intradaily time scales are only produced in the $\mathrm{HC}$ experiment but can not be resolved in the DC experiment.

\subsection{The ENSO asymmetry in observations and models}

The ENSO asymmetry can be measured by the skewness of the monthly Niño-3 index. The skewness is defined as $m_{3} /\left(m_{2}\right)^{3 / 2}$, where $m_{k}$ is the $k$ th centered moment, $m_{k}=\left(\sum_{i=1}^{N}\left(X_{i}-\bar{X}\right)^{k}\right) / N$, where $X_{i}$ is the $i$ th sample of Niño-3 index, $\bar{X}$ is the mean, and $N$ is the number of samples. In the observation (Fig. 1a), the Niño-3 index is positively skewed, with the skewness derived from 100-year Niño-3 index being 0.6. In experiment DC (Fig. 1b), the skewness is underestimated and has a value of 0.3 . The skewness is notably increased to 1.1 when increasing the air-sea coupling frequency to once per hour (Fig. 1c). Note that the skewness of the Niño-3 index is not a fixed value, it varies with time. To assess these variations, we derive a time series of skewness, calculated from overlapping chunks of Niño-3 Index, each having a length of 50 years. The first chunk corresponds to the first 50 years of the 250 -year simulation. The subsequent chunks are obtained by shifting the previous ones forward by one year. The entire 250-year DC and $\mathrm{HC}$ simulations are used for this purpose. As shown in Fig. 5, we got 201 skewness from 250-year simulations. In the beginning of the experiments the skewness of both experiment HC (blue) and DC (red) are close to each other. But after 150 years, the skewness of $\mathrm{HC}$ is generally larger than DC, even though the difference varies with time. The result suggests that the skewness varies strongly over time but the increase of skewness with increasing coupling frequency is a robust feature.

The ENSO asymmetry is not a univariate feature and reveals also prominent spatial characteristics, which can be quantified by composites of SST fields based on Niño-3 Index. The composites derived from the HadISST show that
Fig. 5 Skewness of Niño-3 index over 50-year period derived from running 50-year windows of the entire 250-year DC (red) and HC (blue) simulation

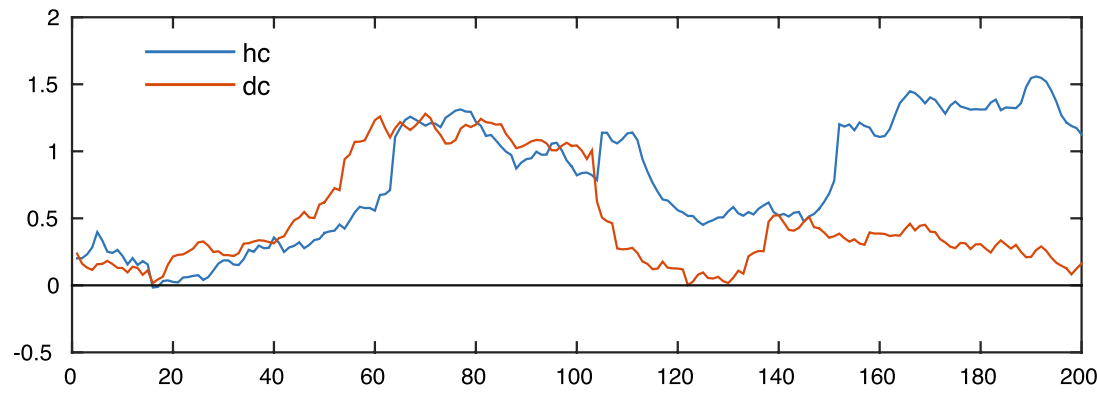


the magnitude of El Niño (Fig. 6d) is stronger than that of La Niña (Fig. 6a). Quantifying the asymmetry in terms of the sum of composites for El Niño and La Niña (Fig. 6g), we find a dipole structure characterized by positive values up to $0.3{ }^{\circ} \mathrm{C}$ in the eastern equatorial Pacific and negative values up to $-0.1{ }^{\circ} \mathrm{C}$ in the western equatorial Pacific. The positive values are not uniformly distributed in the eastern Pacific. Instead two maxima of positive values are found, one located around $150^{\circ} \mathrm{W}$ and the other east of $120^{\circ} \mathrm{W}$.

In the daily coupled experiment, the ENSO asymmetry is underestimated. Though the simulated El Niño (Fig. 6e) is stronger than the simulated La Niña (Fig. 6b), the sum of the two (Fig. 6h) is generally smaller than $0.2{ }^{\circ} \mathrm{C}$ which is $30 \%$ weaker than that found in the observations. When increasing the coupling frequency from daily to hourly, the strength of La Niña is only slightly changed (Fig. 6c), but the magnitude of El Niño (Fig. 6f) becomes considerably larger than that in the daily coupled experiment (Fig. 6e). Thus, the positive values of the sum of El Niño and La Niña increases in the central and eastern Pacific (Fig. 6i), and have magnitudes comparable to those obtained from observations. Therefore, the ENSO asymmetry is better captured by MPI-ESM when increasing the coupling frequency from daily to hourly.

To confirm that the ENSO asymmetry is better captured by hourly coupled MPI-ESM, we consider not only composites in experiments with MPI-ESM at low resolution (MPI-ESM-LR) but also those with MPI-ESM at high resolution (MPI-ESM-HR). As shown in Fig. 7, even though the patterns of asymmetry are different in the experiments with different resolutions, the asymmetry with its characteristic dipole structure is better simulated in hourly coupled experiments (Fig. 7c, e) than in daily coupled experiments (Fig. 7b, d). Note that the pattern of asymmetry is less realistic in MPI-ESM-HR run than in MPI-ESM-LR run. This might be due to the fact that some of the parameterizations of subgrid-scale processes, e.g. that of vertical mixing, are not mofified and retuned when increasing horizontal resolution from $1.5^{\circ}$ to about $0.4^{\circ}$

As suggested by Zhang and Sun (2014), the weaker ENSO asymmetry in the CMIP5 models primarily results from an underestimation of El Niño. In this study, we find increasing the coupling frequency amplifies the amplitude of El Niño (Fig. 6e, f) but does not change the amplitude of La Niña (Fig. 6b, c). It seems that increasing coupling frequency may reduce the underestimation of ENSO asymmetry found in the CMIP5 models.

The result that increasing coupling frequency from daily to hourly enhances the strength of El Niño but has minor effects on the strength of La Niña is not only reflected in SST anomalies, but also in anomalies of LWCF and wind stress. Concentrating on the equatorial Pacific, the composites of SST anomalies (Fig. 8a-c), LWCF anomalies (Fig. 8d-f) and zonal wind stress anomalies (Fig. $8 \mathrm{~g}-\mathrm{i}$ ) reveal clearly larger differences between experiment $\mathrm{HC}$ and $\mathrm{DC}$ in $\mathrm{El}$
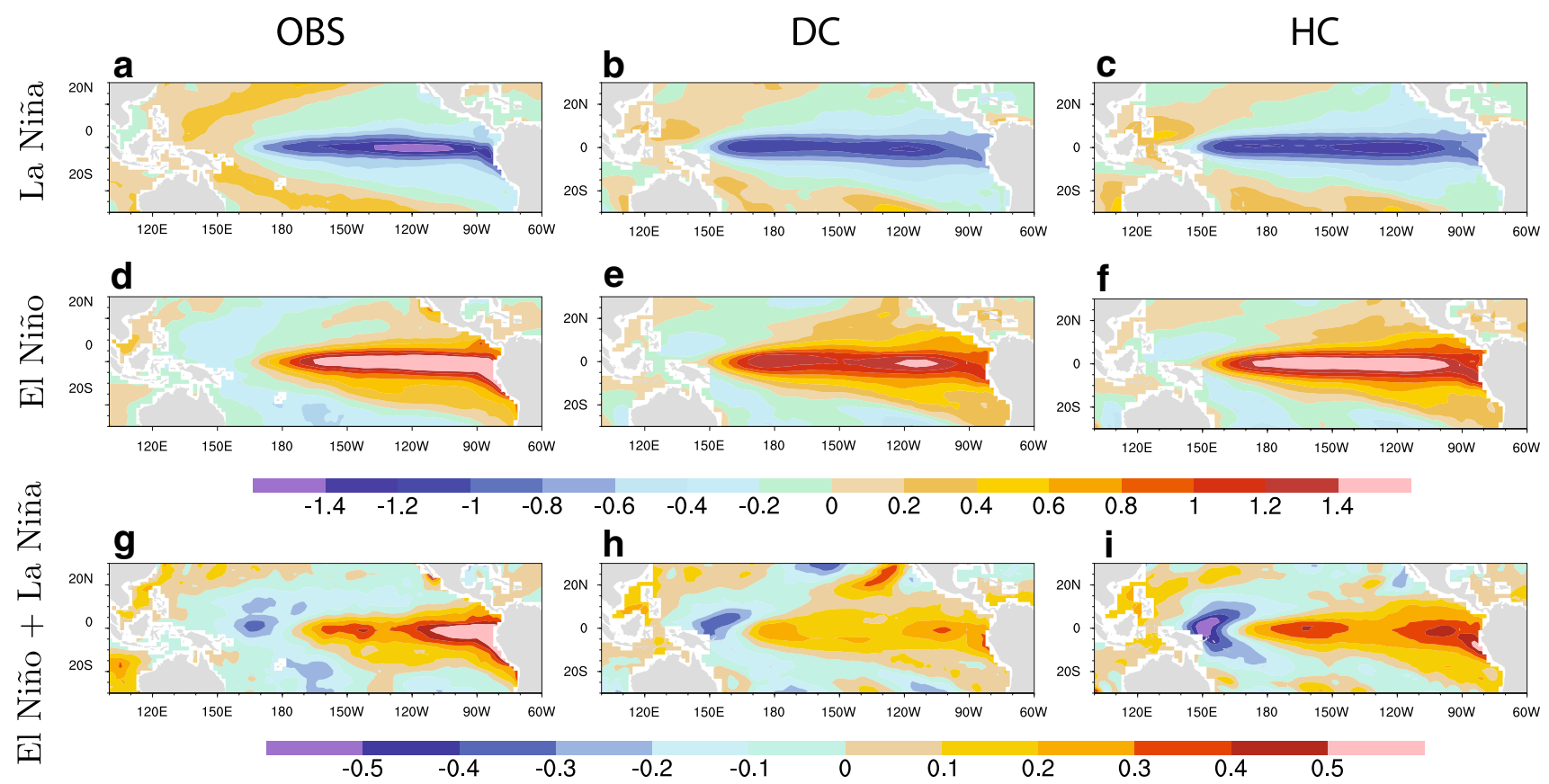

Fig. 6 Composites of SST anomalies (in ${ }^{\circ} \mathrm{C}$ ) for La Niña $(\mathbf{a}-\mathbf{c})$ and El Niño $(\mathbf{d}-\mathbf{f})$ and the sum of the two phases $(\mathbf{g}-\mathbf{i})$, obtained from monthly data from HadISST (a, d, g), experiment DC (b, e, h) and $\mathrm{HC}(\mathbf{c}, \mathbf{f}, \mathbf{i})$. The anomalies are obtained by subtracting the monthly climatological values from the respective monthly time series. The composite of El Niño is obtained when the Niño-3 index is larger than $0.5^{\circ} \mathrm{C}$, the composite of La Niña is obtained when the Niño-3 index is smaller than $-0.5^{\circ} \mathrm{C}$ 


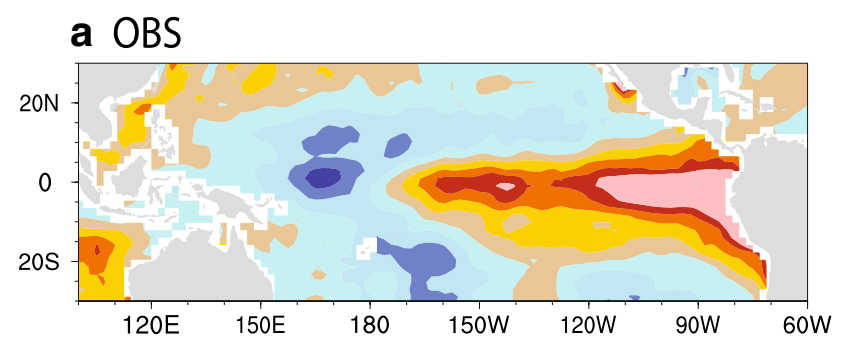

b LRDC

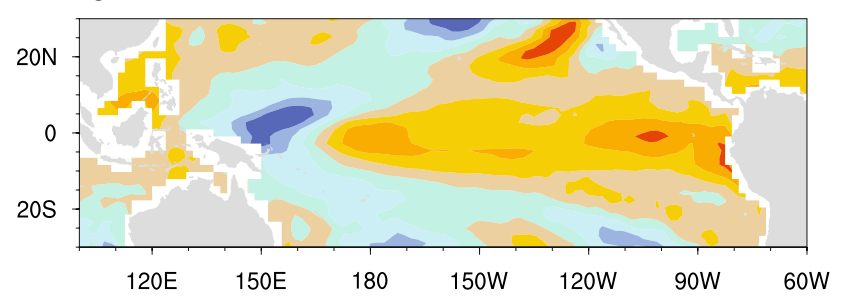

d HRDC

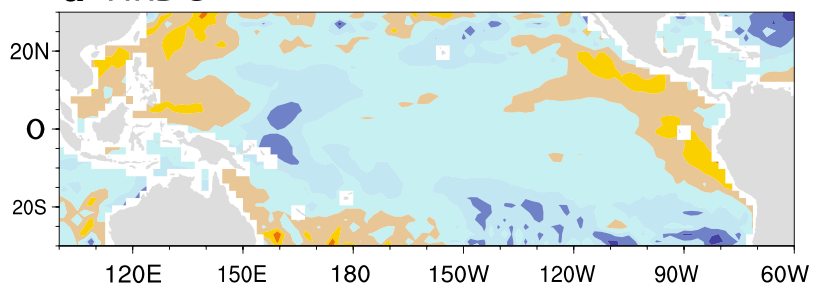

c $\mathrm{LRHC}$

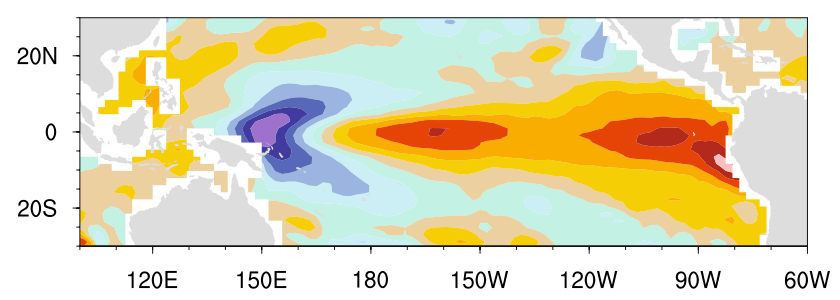

e $\mathrm{HRHC}$

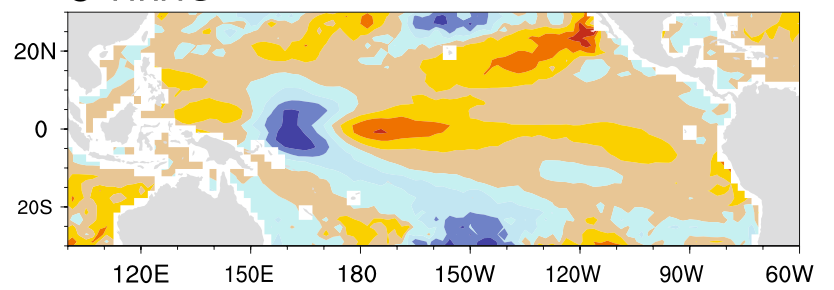

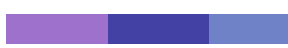

\section{$-0.4-0.3-0.2-0.1$}

Fig. 7 The sum of SST anomalies (in ${ }^{\circ} \mathrm{C}$ ) in El Niño and La Niña events for a obtained from HadISST, $\mathbf{b}, \mathbf{c}$ from low resolution MPIESM (MPI-ESM-LR), d, e from high resolution MPI-ESM (MPI-

Niño events (left column) than in La Niña events (middle column). These differences lead to the asymmetry shown in the right column.

The left column of Fig. 8 further suggests that during a warm event, the Bjerknes feedback is present in both experiment HC and DC. The positive SST and LWCF anomalies over the central and eastern equatorial Pacific are corresponding to the positive zonal wind stress anomalies over the central equatorial Pacific and negative wind stress anomalies over the eastern equatorial Pacific. This relation indicates enhanced convection over the central Pacific and the associated wind changes, especially the weakening of the trade winds over the central equatorial Pacific. The changes in trade winds can further feedback and enhance the anomalies of SST and LWCF. The strength of this known Bjerknes feedback is affected by the coupling frequency: It is noticeably stronger in experiment $\mathrm{HC}$ than in DC, in particular in the region around $180^{\circ}-150^{\circ} \mathrm{W}$, near one of the maxima of the dipole structure shown in Fig. 6. We will come back
ESM-HR). b, d the results from daily coupled experiments; $\mathbf{c}, \mathbf{e}$ are the results of hourly coupled experiments

to this region latter. During a cold event, the composites derived from the two experiments are comparable to each other.

\subsection{The role of diurnal cycle of SST anomalies in ENSO asymmetry}

As shown in Figs. 2 and 3, the amplitude of diurnal range of SST in experiment $\mathrm{HC}$ is about $0.2{ }^{\circ} \mathrm{C}$. During El Niño events, the background SST in the central and eastern tropical Pacific is warmer than normal. The diurnal cycle of SST anomalies can produce additional warming and trigger more convection. During the La Niña phase, the background SST is colder than normal and convection is absent in the central eastern equatorial Pacific. The diurnal cycle of SST anomalies has little influence on convection. This makes us to assume that convection is more sensitive to the diurnal cycle of SST anomalies in El Niño years than in La Niña years. The different sensitivity of convection to the diurnal 

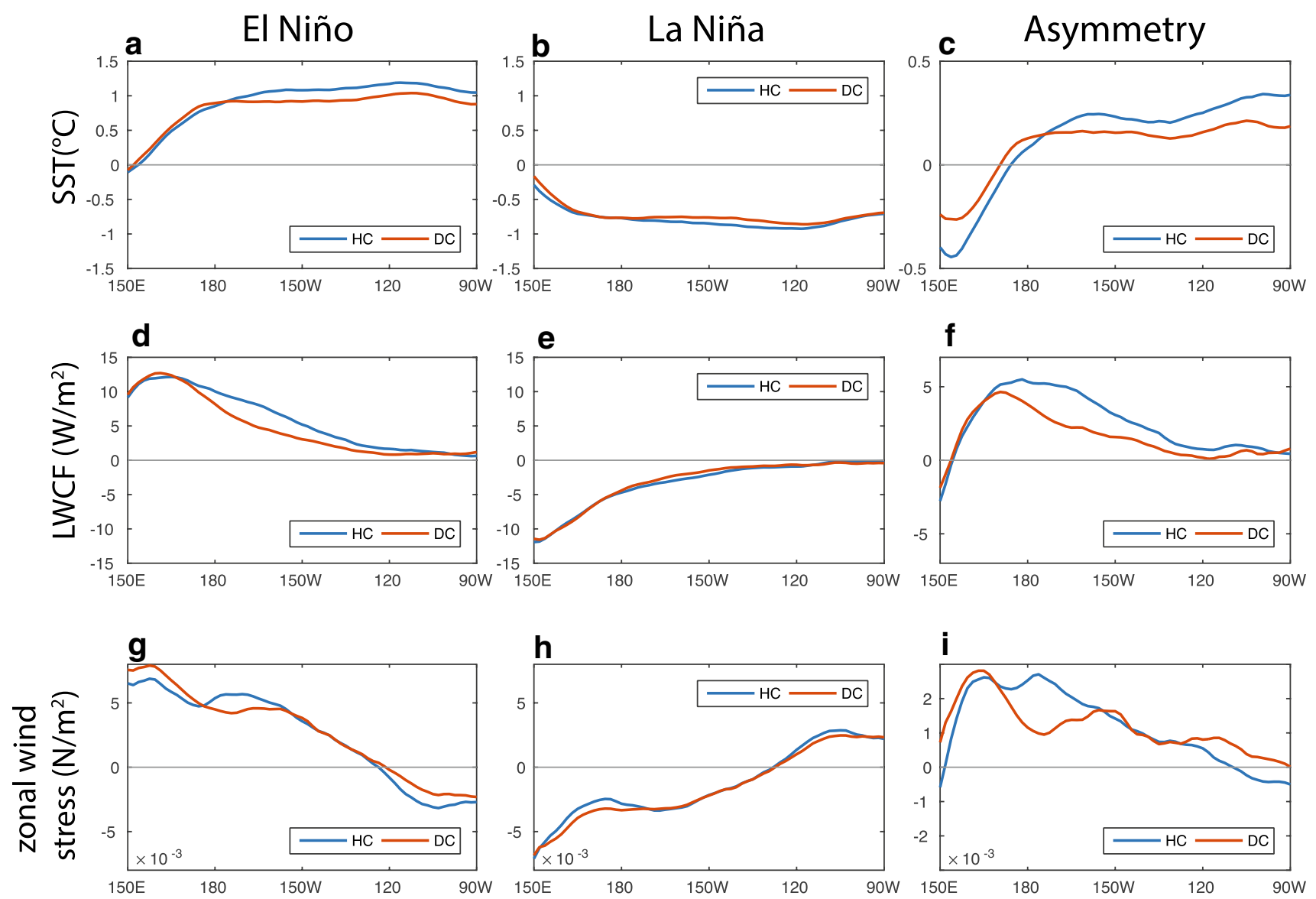

Fig. 8 Meridional mean $\left(5^{\circ} \mathrm{S}-5^{\circ} \mathrm{N}\right)$ of the composited anomalies of SST $\left(\mathbf{a}-\mathbf{c}\right.$ in $\left.{ }^{\circ} \mathrm{C}\right)$, LWCF $\left(\mathbf{d}-\mathbf{f}\right.$ in $\left.\mathrm{W} / \mathrm{m}^{2}\right)$ and zonal wind stress $(\mathbf{g}-\mathbf{i}$ in $\left.\mathrm{N} / \mathrm{m}^{2}\right)$ in El Niño $(\mathbf{a}, \mathbf{d}, \mathbf{g})$, La Niña $(\mathbf{b}, \mathbf{e}, \mathbf{h})$ and the sum of the two phases $(\mathbf{c}, \mathbf{f}, \mathbf{i})$. The anomalies are obtained from 100-year DC and

HC by subtracting the monthly climatological values from the respective monthly time series. The composite of El Niño is obtained when the Niño-3 index is larger than $0.5{ }^{\circ} \mathrm{C}$, the composite of La Niña is obtained when the Niño-3 index is smaller than $-0.5^{\circ} \mathrm{C}$

cycle of SST anomalies can be further amplified via Bjerknes feedback, leading eventually to the asymmetry in ENSO.

We examine this assumption using the 9 pairs of daily and hourly coupled experiments ( $\mathrm{HCi}$ and $\mathrm{DCi}$ ). Each pair of $\mathrm{HCi}$ and DCi used the same restart data, indicating that all the oceanic and atmospheric variables from the same initial state. The differences between the convective activities in each pair of experiments is caused solely by the diurnal cycle of SST anomalies which is simulated in the hourly coupled experiment but not in the daily coupled experiment. The average over the three cases for normal, El Niño, and La Niña initial conditions, respectively, quantifies the role of SST diurnal cycle during these different phases of ENSO.

The strength of convection is quantified by the composites of LWCF anomalies obtained from the ERA-Interim OLR. As shown in Fig. 9, the enhanced convection over western tropical Pacific in La Niña years (Fig. 9a) indicates enhanced Walker circulation. The negative convection anomalies over the western Pacific and positive anomalies over the central and eastern Pacific (Fig. 9b) in El Niño years indicate a eastward shift of the Walker circulation. Consistent with the asymmetry in SST, the amplitude of convection anomalies in El Niño years is stronger than that in La Niña years, leading to a non-zero sum of the two composites. This sum (Fig. 9c) shows positive anomalies in central and eastern Pacific and negative anomalies in the western Pacific, with the maximum (blue star) located around $\left(0^{\circ}, 165^{\circ} \mathrm{W}\right)$. Given this structure of asymmetry in convection, we choose this grid point $\left(0^{\circ}, 165^{\circ} \mathrm{W}\right)$ to study the response of convection to the diurnal cycle of SST anomalies during different phases of ENSO.

The diurnal cycle of SST anomalies involved in the hourly coupled experiment affects the convection by changing the air-sea temperature difference. If SST is warmer than the surface air temperature, there will be more heat and moisture transport to the atmosphere, which can increase the atmospheric moist instability. When the atmospheric moist instability reaches a certain threshold, convection can be triggered. To explore this possibility, we studied the mean diurnal cycle of the difference between SST and 
Fig. 9 Composites of LWCF anomalies (in $\mathrm{W} / \mathrm{m}^{2}$ ) for $\mathrm{La}$ Niña (a) and El Niño (b) and the sum of El Niño and La Niña (c) from ERA-Interim data. The anomalies are obtained by subtracting the monthly climatological values from the respective monthly time series. The composites of El Niño are obtained when the Niño-3 index in HadISST is larger than 0.5 ${ }^{\circ} \mathrm{C}$, the composites of La Niña are obtained when the Niño-3 index in HadISST is smaller than $-0.5^{\circ} \mathrm{C}$

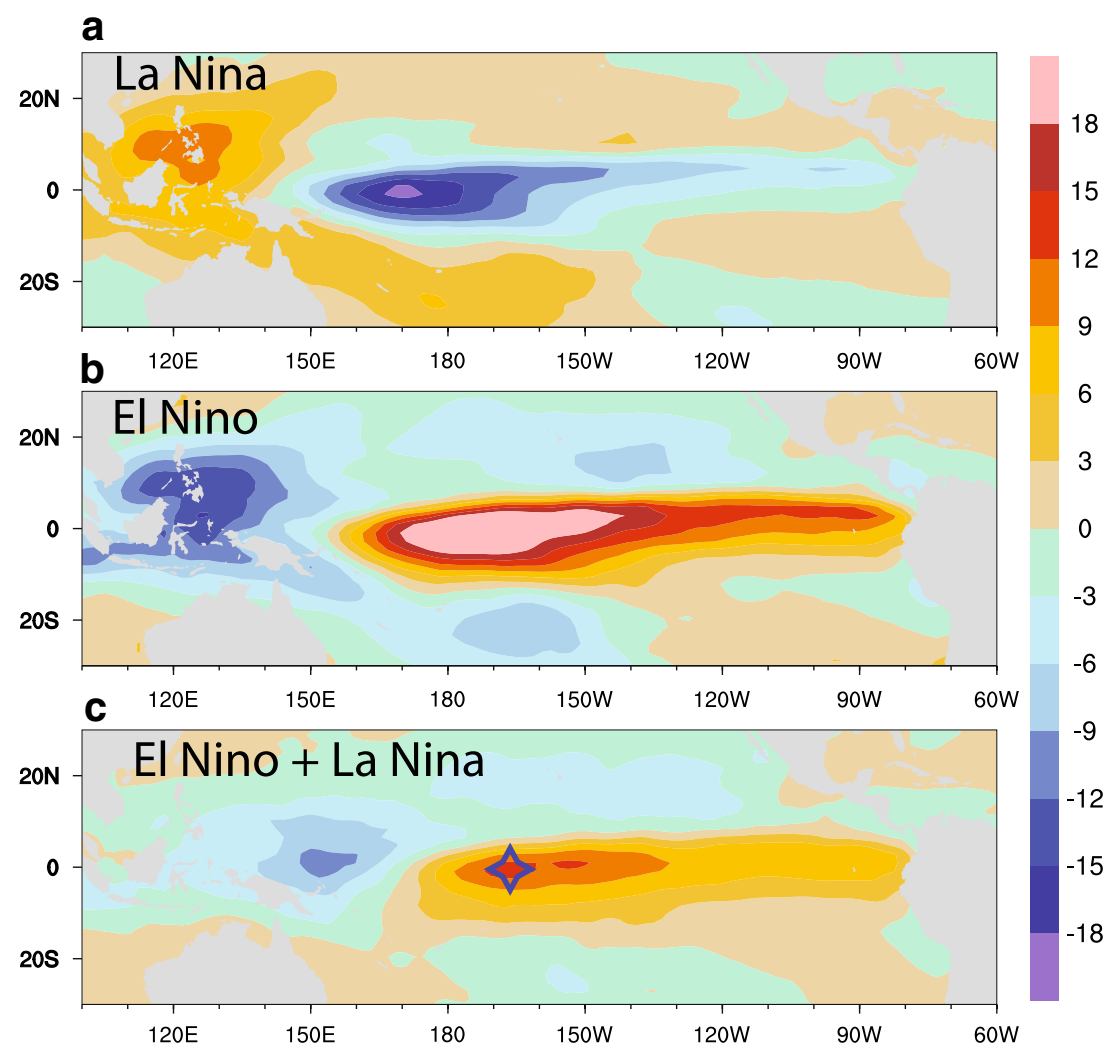

2m air-temperature (SST-T2m), the K-index and LWCF in the selected El Niño (red), La Niña (blue) and neutral years (black) (Fig. 10). Note that independent of coupling frequency, all atmospheric variables can possess a diurnal cycle, due to the diurnal cycle in solar radiation. However, these atmospheric diurnal cycles can be either enhanced or suppressed, depending on whether the diurnal cycle in SST is resolved in experiment $\mathrm{HC}$ or completely suppressed in experiment DC.

The difference of SST-T2m is generally larger in the early morning (around $3 \mathrm{AM}-4 \mathrm{AM}$ ) than in the early evening (around $8 \mathrm{PM}$ ). Relative to that in normal years, difference of SST-T2m is larger in El Niño years and smaller in La Niña years (Fig. 10a). When resolving the diurnal cycle in SST in experiment HC, the difference SST-T2m in El Niño years is further increased throughout the whole day (solid red line relative to dashed red line), with the maximum increase reaching about $0.17^{\circ} \mathrm{C}$ around $3 \mathrm{PM}$ local time.

Changes in the diurnal cycle in SST-T2m lead to changes in the moist instability quantified by the K-index (Fig. 10b). Generally, the atmospheric moist stability is stronger when the back-ground SST is warm (i.e. in El Niño years, red lines) and weaker when the background SST is cold (i.e. in neutral and La Niña years, black and blue lines). The overall increase in SST-T2m in El Niño years induced by resolving the diurnal cycle in SST systematically enhances the moist instability in El Niño years (red lines). Such an enhancement in moist instability is not seen in the neutral and La Niña years, since the background SST is low and the convection is absent in these years at the selected site. In the La Niña years, resolving the diurnal cycle in SST leads even to a reduction in moist instability (equivalent to an increase in moist stability).

The convection is normally generated when the atmospheric moist instability reaches a certain level. Since the diurnal cycle of SST anomalies has different effects on the atmospheric moist instability in different phase of ENSO, different responses of convection to the diurnal cycle of SST anomalies during different phases of ENSO are expected. Indeed, convective activity, which is strong in El Niño years but much less evident in the neutral and La Niña years, is further enhanced by resolving the diurnal cycle of SST anomalies in the El Niño years, but essentially unchanged in the neutral and La Niña years.

In El Niño years, the effect of SST diurnal cycle on moist instability and on convection is further demonstrated by considering the timing of the maximum changes in SST-T2m, K-index and LWCF induced by hourly coupling (Fig. 11). Three different grid points in the central equatorial Pacific are considered. In all three cases, the timing of the maximum change in SST-T2 $m$ induced by hourly coupling leads the timing of maximum change in K-index and in LWCF, with the maximum of SST-T2m occurring at about 4 PM, the maximum K-index at about 6-7 PM and the maximum 

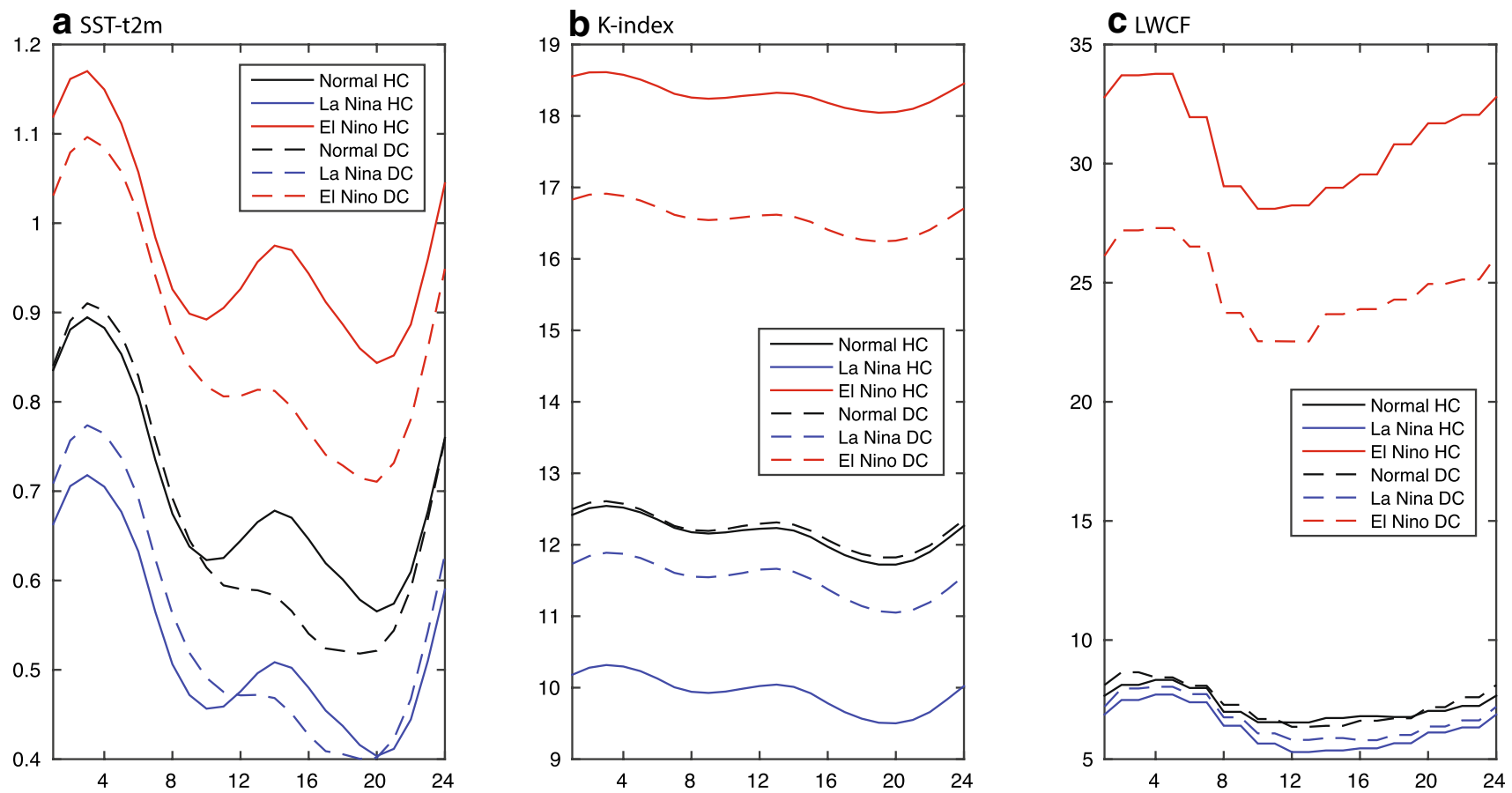

Fig. 10 3-year mean diurnal cycle of a SST-t2m (in ${ }^{\circ} \mathrm{C}$ ), b K-index and $\mathbf{c}$ LWCF (in W/m $/ \mathrm{m}^{2}$ ) over one grid point near $\left(0^{\circ}, 165^{\circ} \mathrm{W}\right.$ ) in Neutral year (black), El Niño year (red) and La Niña year (blue) in experiment HCi (solid) and DCi (dashed)
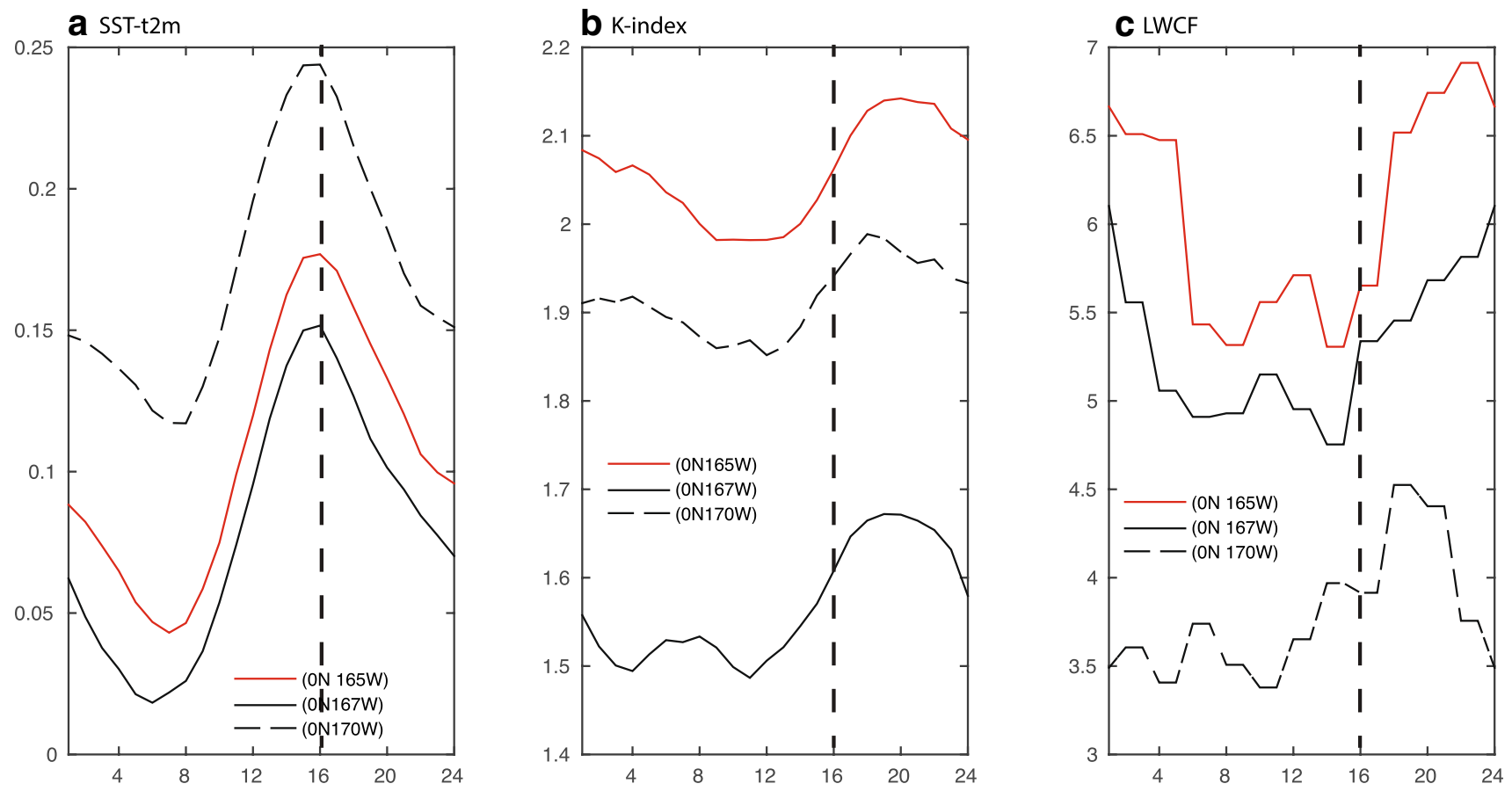

Fig. 11 The difference of a SST-t2m (in $\left.{ }^{\circ} \mathrm{C}\right)$, b K-index and $\mathbf{c} \mathrm{LWCF}\left(\mathrm{W} / \mathrm{m}^{2}\right)$ between HCi and DCi (HCi-DCi) in El Niño years on grid point near $\left(0^{\circ}, 165^{\circ} \mathrm{W}\right)($ red $),\left(0^{\circ}, 167^{\circ} \mathrm{W}\right)$ (black solid) and near $\left(0^{\circ}, 170^{\circ} \mathrm{W}\right)$ (black dashed) 
in convection at about or after 7 PM. This relationship is consistent with the idea that resolving diurnal cycle of SST anomalies produces an increase in SST-T2 $\mathrm{m}$ and with that an increase in moist instability that triggers convection.

The different responses of convection to the diurnal cycle of SST anomalies in different phases of ENSO are consistent with the spatial distribution of the changes of SST-T2m and LWCF in Fig. 12. In neutral and La Niña years, SST-T2m and convection increases in a small region over the western tropical Pacific. In El Niño years, however, SST-T2m increases in a large region over the central tropical Pacific, in particular in the equatorial Pacific extending from $150^{\circ} \mathrm{E}$ to $150^{\circ} \mathrm{W}$, where the convection also increases.

Therefore, in El Niño years, diurnal cycle of SST anomalies amplifies the atmospheric moist instability. The atmospheric moist instability leads to more convection at nighttime. The enhanced convection over the central tropical Pacific further weakens easterlies near $180^{\circ}-160^{\circ} \mathrm{W}$, whereby amplifying the warm SST anomalies via Bjerknes feedback, leading to stronger El Niño events. In La Niña years, the diurnal cycle of SST anomalies has little effect on the amplitude of SST anomalies, since the background SST is too low to support convection.

\section{Concluding remarks}

This paper investigates the ENSO asymmetry within the framework of MPI-ESM-1.2. We found the following:
First, the simulated ENSO asymmetry can be amplified by increasing the air-sea coupling frequency. When increasing the coupling frequency from once per day to once per hour, the skewness of the Niño-3 Index is amplified, because the higher coupling frequency produces on average stronger warm events, while leaving the cold events essentially unchanged. In the equatorial Pacific, the resulting asymmetry, as quantified by the sum of the composites related to the warm and cold events, reveals warmer SST, enhanced convection and weakened easterlies in the central Pacific near $170^{\circ} \mathrm{E}-150^{\circ} \mathrm{W}$. This suggests that the Bjerknes feedback is enhanced by increasing coupling frequency.

Secondly, the enhanced ENSO asymmetry seems to result from the inclusion of the diurnal cycle of SST anomalies that has stronger effects on convections during the El Niño events. In neutral years or during La Niña events, the background SST in the central equatorial Pacific is cold. The diurnal cycle of SST anomalies has little impact on convection. During warm events, on the contrary, resolving diurnal cycle of SST anomalies increases the difference between SST and $2 \mathrm{~m}$ air temperature (SST-T2m), which amplifies the moist instability and the convective activity. The enhanced convection can further feedback to the SST, making the Bjerknes feedback stronger in hourly coupled experiment than in daily coupled experiment.

The above conclusions are drawn from experiments carried out with the MPI-ESM at a low horizontal resolution. When increasing the horizontal resolution in both the atmosphere and the ocean, qualitatively similar results
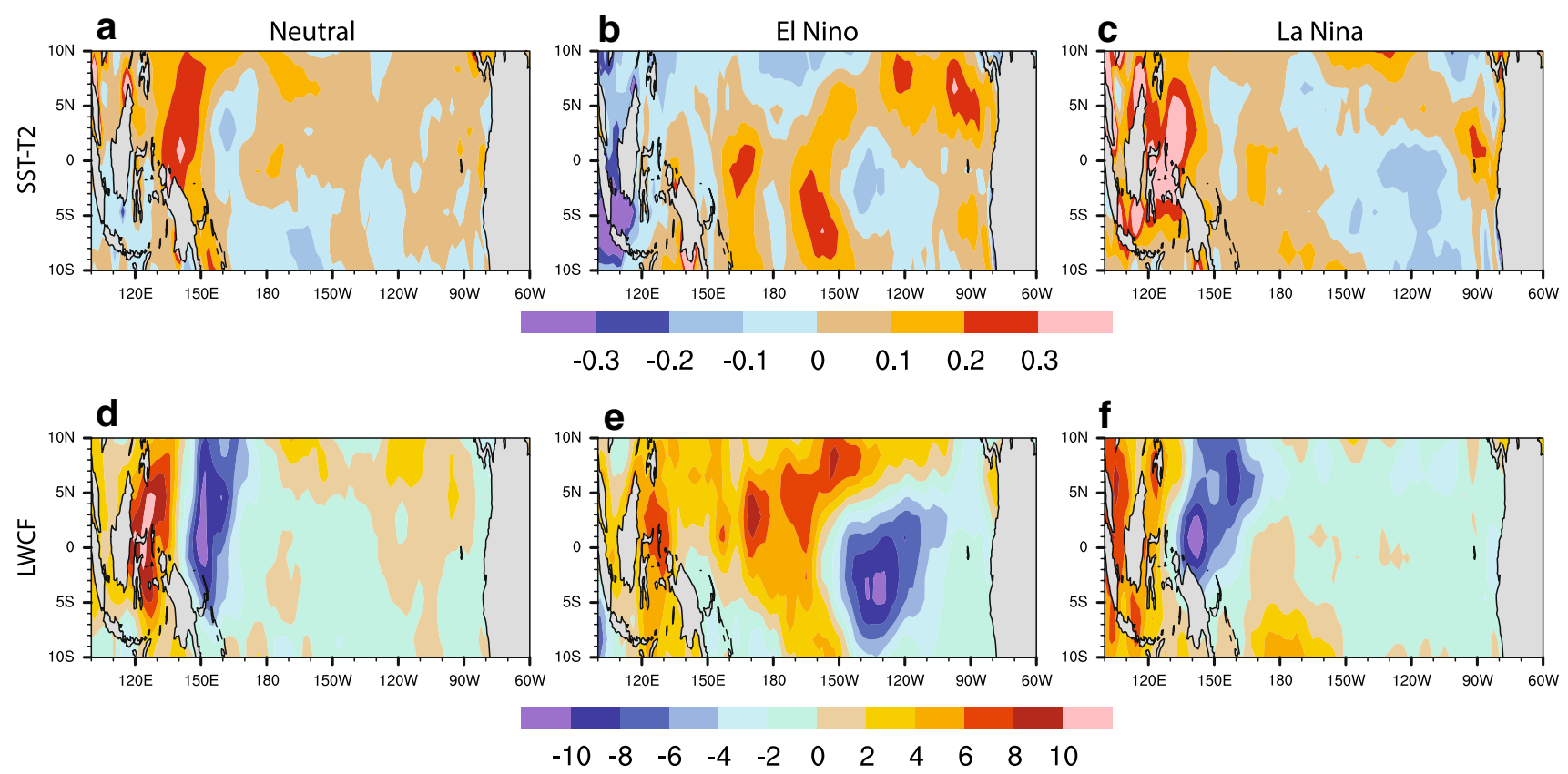

Fig. 12 Difference of SST-T2m $\left({ }^{\circ} \mathrm{C}\right)(\mathbf{a}-\mathbf{c})$ and LWCF $\left(\mathrm{W} / \mathrm{m}^{2}\right)(\mathbf{d}-\mathbf{f})$ between experiment HCi and DCi (HCi-DCi) in Neutral years (a, d), El Niño years $(\mathbf{b}, \mathbf{e})$ and La Niña years $(\mathbf{c}, \mathbf{f})$ 
are found, even though the spatial structures of the asymmetry seems to vary with resolution. The main result that increasing coupling frequency enhances the ENSO asymmetry applies also to experiments using MPI-ESM at a higher resolution.

Note that the skewness in $\mathrm{HC}$ is close to that in experiment DC in the beginning of simulation. This might due to the fact that the effect of intra-daily air-sea interaction on ENSO asymmetry has to be accumulated over time and longer spin-up time is needed for the effect of hourly coupling to become visible. This might also due to the multidecadal variability of ENSO asymmetry. The multi-decadal variability of the skewness of Niño-3 index can also be seen in observation (not shown). Further investigations are required to clarify the role of spin-up time and the multidecadal variability of ENSO asymmetry.

It is noted that the MPI-ESM has a quite thick surface layer of $12 \mathrm{~m}$ deep. Using an ocean model with a thinner surface layer may give a different sensitivity of model convection to the diurnal cycle of SST anomalies. Certainly, the convection parametrization used in ECHAM6 may also alter the result. Further investigations are required to clarify these issues.

Acknowledgements We thank Juergen Bader and the two anonymous reviewers for helpful comments and the German Climate Computer Center (DKRZ) for making the simulations possible. We thank Helmuth Haak for assisting in the numerical experiments. Fangxing Tian was financially supported by Chinese Academy of Science (CAS), Max Planck Institute for Meteorology (MPI-M), Max Planck Society (MPG) and International Max Planck Research School on Earth System Modelling (IMPRS-ESM) and UK-China Research Innovation Partnership Fund through the Met Office Climate Science for Service Partnership (CSSP) China as part of the Newton Fund. This work was supported through the Cluster of Excellence 'CliSAP' (EXC177), University of Hamburg, funded through the German Science Foundation (DFG). The data used in the study are available on request (jin-song.von-storch@ mpimet.mpg.de).

Open Access This article is distributed under the terms of the Creative Commons Attribution 4.0 International License (http://creativeco mmons.org/licenses/by/4.0/), which permits unrestricted use, distribution, and reproduction in any medium, provided you give appropriate credit to the original author(s) and the source, provide a link to the Creative Commons license, and indicate if changes were made.

\section{References}

An S-I, Ham Y-G, Kug J-S, Fei-Fei J, Kang I-S (2005) El niño-la niña asymmetry in the coupled model intercomparison project simulations*. J Clim 18(14):2617-2627

An S-I, Jin F-F (2004) Nonlinearity and asymmetry of enso*. J Clim 17(12):2399-2412

An S-I, Kug J-S, Ham Y-G, Kang I-S (2008) Successive modulation of enso to the future greenhouse warming. J Clim 21(1):3-21
Bernie D, Guilyardi E, Madec G, Slingo J, Woolnough S, Cole J (2008) Impact of resolving the diurnal cycle in an ocean-atmosphere $\mathrm{gcm}$. part 2: A diurnally coupled cgcm. Clim Dyn 31(7-8):909-925

Burgers G, Stephenson DB (1999) The "normality" of el niño. Geophysical Research Letters 26(8):1027-1030. https://doi. org/10.1029/1999GL900161.

Clayson CA, Bogdanoff AS (2013) The effect of diurnal sea surface temperature warming on climatological air-sea fluxes. J Clim 26(8):2546-2556

Danabasoglu G, Large WG, Tribbia JJ, Gent PR, Briegleb BP, McWilliams JC (2006) Diurnal coupling in the tropical oceans of CCSM3. J Clim 19(11):2347-2365

Dee Dick P, Uppala SM, Simmons AJ, Paul Berrisford P, Kobayashi Poli S, Andrae U, Balmaseda MA, Balsamo G, DP Bauer et al. (2011) The era-interim reanalysis: Configuration and performance of the data assimilation system. Quart J R Meteorol Soc 137(656):553-597

George JJ (2014) Weather forecasting for aeronautics. Academic press

Gille S (2012) Diurnal variability of upper ocean temperatures from microwave satellite measurements and argo profiles. J Geophys Res Oceans (1978-2012) 117(C11027):1-10

Guilyardi E et al (2004) Representing el niño in coupled ocean-atmosphere gcms: the dominant role of the atmospheric component. J Clim 17(24):4623-4629

Hoerling MP, Kumar A, Zhong M (1997) El niño, la niña, and the nonlinearity of their teleconnections. J Clim 10(8):1769-1786

Im S-H, An S-I, Kim ST, Jin F-F (2015) Feedback processes responsible for el niño-la niña amplitude asymmetry. Geophys Res Lett 42(13):5556-5563

Jungclaus $J$ et al (2006) Ocean circulation and tropical variability in the coupled model echam5/mpi-om. J Clim 19(16):3952-3972

Jungclaus J et al (2010) Climate and carbon-cycle variability over the last millennium. Clim Past Discuss 6(3):1009-1044

Kang IS, Kug JS (2002) El niño and la niña sea surface temperature anomalies: asymmetry characteristics associated with their wind stress anomalies. J Geophys Res Atmos (1984-2012) 107(D19):1-10

Kennedy J, Brohan P, Tett S (2007) A global climatology of the diurnal variations in sea-surface temperature and implications for msu temperature trends. Geophys Res Lett 34:1-5

Li Y, Han W, Shinoda T, Wang C, Lien R-C, Moum JN, Wang J-W (2013) Effects of the diurnal cycle in solar radiation on the tropical indian ocean mixed layer variability during wintertime madden-julian oscillations. J Geophys Res Oceans 118(10):4945-4964

Masson S, Terray P, Madec G, Luo J-J, Yamagata T, Takahashi K (2012) Impact of intra-daily sst variability on enso characteristics in a coupled model. Clim Dyn 39(3-4):681-707

Matsangouras I, Nastos P, Bluestein H, Pytharoulis I, Papachristopoulou K, Miglietta M (2016) Analysis of waterspout environmental conditions and of parent-storm behaviour based on satellite data over the southern aegean sea of greece. Int J Climatol 32(2): 1022-1039

Meehl G, Lukas R, Kiladis G, Weickmann K, Matthews A, Wheeler M (2001) A conceptual framework for time and space scale interactions in the climate system. Clim Dyn 17(10):753-775

Rayner N, Parker DE, Horton E, Folland C, Alexander L, Rowell D, Kent E, Kaplan A (2003) Global analyses of sea surface temperature, sea ice, and night marine air temperature since the late nineteenth century. J Geophys Res: Atmos 108(D14):1-29

Serbis E, Lolis C, Kassomenos P (2013) Atmospheric circulation characteristics associated with high static instability conditions over the athens region. Advances in Meteorology, Climatology and Atmospheric Physics, Springer, pp 717-722

Stevens B et al (2013) Atmospheric component of the mpi-m earth system model: Echam6. J Adv Model Earth Syst 5(2):146-172 
Tang Y, Hsieh WW (2003) Nonlinear modes of decadal and interannual variability of the subsurface thermal structure in the pacific ocean. J Geophys Res Oceans (1978-2012) 108(C3):1-12

Terray P, Kamala K, Masson S, Madec G, Sahai A, Luo J-J, Yamagata $\mathrm{T}$ (2012) The role of the intra-daily sst variability in the indian monsoon variability and monsoon-enso-iod relationships in a global coupled model. Clim Dyn 39(3-4):729-754

Thushara V, Vinayachandran P (2014) Impact of diurnal forcing on intraseasonal sea surface temperature oscillations in the Bay of Bengal. J Geophys Res: Oceans 119(12):8221-8241

Tian B, Fan K (2013) Factors favorable to frequent extreme precipitation in the upper Yangtze river valley. Meteorol Atmos Phys 121(3-4):189-197

Tian F, von Storch J-S, Hertwig E (2016) Air-sea fluxes in a climate model using hourly coupling between the atmospheric and the oceanic components. Clim Dyn 48(9-10):2819-2836

Timmermann A, Jin F-F, Abshagen J (2003) A nonlinear theory for el niño bursting. J Atmos Sci 60(1):152-165

Valcke S, Caubel A, Declat D, Terray L (2003) OASIS ocean atmosphere sea ice soil user's guide. Tech rep Cent Eur Formation Avancee Calcul Sci 85, Toulouse, France
Vialard J, Menkes C, Boulanger J-P, Delecluse P, Guilyardi E, McPhaden MJ, Madec G (2001) A model study of oceanic mechanisms affecting equatorial pacific sea surface temperature during the 1997-98 el niño. J Phys Oceanogr 31(7):1649-1675

Watanabe M, Chikira M, Imada Y, Kimoto M (2011) Convective control of ENSO simulated in MIROC. J Clim 24(2):543-562

Weller RA, Majumder S, Tandon A (2014) Diurnal restratification events in the southeast Pacific trade wind regime. J Phys Oceanogr 44(9):2569-2587

Yang Y, Li T, Li K, Yu W (2015) What controls seasonal variations of the diurnal cycle of sea surface temperature in the eastern tropical Indian Ocean?*. J Clim 28(21):8466-8485

Yu J-Y, Liu WT (2003) A linear relationship between enso intensity and tropical instability wave activity in the eastern Pacific Ocean. Geophys Res Lett 30(14):1-4

Zhang T, Sun D-Z (2014) ENSO asymmetry in CMIP5 models. J Clim 27(11):4070-4093

Zhang T, Sun D-Z, Neale R, Rasch PJ (2009) An evaluation of enso asymmetry in the community climate system models: a view from the subsurface. J Clim 22(22):5933-5961 